\title{
Scientific landscape and trend analysis of keloid research: a 30-year bibliometric review
}

\author{
Yuming Chong ${ }^{1}$, Xiao Long ${ }^{1}$, Yuh-Shan $\mathrm{Ho}^{2}$ \\ ${ }^{1}$ Department of Plastic and Aesthetic Surgery, Peking Union Medical College Hospital, Chinese Academy of Medical Sciences \& Peking Union \\ Medical College, Beijing, China; ${ }^{2}$ Trend Research Centre, Asia University, Taichung 41354 \\ Contributions: (I) Conception and design: All authors; (II) Administrative support: X Long; (III) Provision of study materials or patients: YS Ho; (IV) \\ Collection and assembly of data: YS Ho; (V) Data analysis and interpretation: Y Chong, YS Ho; (VI) Manuscript writing: All authors; (VII) Final \\ approval of manuscript: All authors. \\ Correspondence to: Xiao Long. Peking Union Medical College Hospital, No. 1, Shuaifuyuan, Dongcheng District, Beijing, China. \\ Email: longxiao@pumch.cams.cn; xiao.longpumch@outlook.com; Yuh-Shan Ho. Trend Research Centre, Asia University, No. 500, Lioufeng Road, \\ Wufeng, Taichung 41354. Email: ysho@asia.edu.tw.
}

Background: Keloids remain troublesome for clinicians because of the lack of standard therapy, and the underlying mechanisms are still unclear. Bibliometric analysis could be a powerful tool to comprehensively review research trends, evaluate publication performances and provide future perspectives. There is no bibliometric analysis focusing on keloid research.

Methods: Keloid related publications were searched in Web of Science Core Collection from the publication year 1990 to 2019. Bibliometric data were provided on document type, annual publication number, most productive journals, publication geography, top potential authors, and highly cited articles. The distribution of single words in article titles was analyzed to evaluate the main research focuses and determine their development trends. Word cluster analysis was further performed to detect emerging trends in keloid research.

Results: The number of annual articles increased from 24 in 1990 to 63 in 2006 and then increased sharply, reaching 139 in 2019. Dermatologic Surgery published the highest number of articles followed by Plastic and Reconstructive Surgery. The USA ranked top with six publication indicators and China had a dramatic increase in the annual number of articles since 2012. Recent research hotspots include underlying pathogenetic mechanisms, keloid treatment, and therapeutic effect evaluation.

Discussion: Keloids remain a research focus. Efforts will be continuously made to understand the underlying mechanism of keloid formation. Despite many treatment modalities, there is no gold standard for keloid treatment, and many efforts are being made in the exploration of new therapies. Moreover, it is foreseeable that objective measurement tools will have a higher status in the assessment of keloids and scars.

Keywords: Keloid; bibliometric; citation analysis; Web of Science Core Collection; research trends

Submitted Feb 02, 2021. Accepted for publication Apr 23, 2021.

doi: $10.21037 /$ atm-21-508

View this article at: http://dx.doi.org/10.21037/atm-21-508

\section{Introduction}

Keloids are characterized by aberrant production of collagen fibers that are longer, thicker, and more randomly oriented than normal $(1,2)$. Other biochemical features include a high fibroblast proliferation rate, increased enzyme concentrations, and growth factors stimulation (3-5). Keloids can lead to pain, pruritus, and cosmetic problems (6). Many efforts have been made to establish a gold standard in keloid treatment, but to date, a consensus has not been reached for standard therapy (7).

Bibliometric analysis provides information on the annual 
number of publications, citation life of articles, topicrelated journals, publication performances of authors and institutions, and research trends. These bibliometric profiles illustrate important studies, the authority, journals that favor related publications, and the focus of future studies. Experienced researchers who are eager to know the frontier or individuals who intend to start research will benefit from a bibliometric study.

Bibliometrics has been applied to other medical topics including pain, Ebola, dengue, HIV, and pneumonia (8-12). It is surprising that there is no bibliometric analysis focusing on such an old disease which has been intensively studied because of unsettled problems concerning not only pathogenesis but also treatment. Bibliometric analysis could be a powerful tool to comprehensively review research trends, evaluate publication performances and provide future perspectives. This bibliometric study aims to map the research landscape of keloids and, more importantly, identify research trends to assist researchers in future directions.

We present the following article in accordance with the PRISMA reporting checklist (available at http://dx.doi. org/10.21037/atm-21-508).

\section{Methods}

It has been pointed out that it is not appropriate to use all databases which are not in the same level in Web of Science for bibliometric studies $(13,14)$. The data in this study was through the Science Citation Index Expanded (SCIEXPANDED) database of the Clarivate Analytics Web of Science Core Collection (Data last updated on March 10, 2021). After our pre-study, the search keywords: "keloid", "keloids", "keloider", "keloides", "keloide", "keloidi", "keloidentwicklung", "keloiddisposition", "keloidsdten", "keloidlike", "keloidogenesis", "keloidosis", "keloidiformis", "keloidectomy", "keloidal", "intrakeloid", "narbenkeloid", and "antikeloid" were searched in the Topic field, including title, abstract, author keywords, and KeyWords Plus, in the Web of Science Core Collection within the publication year limitation from 1990 to 2019. The retrieving time of a bibliometric analysis usually starts from 1991 because many publications in SCI-EXPANDED before that are lack of abstracts. However, in this study, the publication year was limited from 1990 because in this way the research focuses and development trends could be observed in the past three decades (1990s, 2000s, and 2010s). KeyWords Plus supplies additional search terms extracted from the titles of articles cited by authors in their bibliographies and footnotes in the
ISI (now Clarivate Analytics) database, and substantially augments title-word and author-keyword indexing (15). This resulted 3,997 documents (not including the document type of early access) as keloid related publications. Those documents only found by KeyWords Plus are more likely to be unrelated to the "keloid" (16). Ho's group firstly proposed the "front page" filter (17-19) — which covers only documents with searching keywords in their "front page", including only the title, abstract, and author keywords; this filter might avoid introducing unrelated publications for analysis (17). Finally, 3,394 documents (85\% of 3,997 documents) were defined as keloid research publications. The full record of SCI-EXPANDED and the number of citations in each year for each document were downloaded into Microsoft Excel 2016 and checked. Additional coding was manually performed $(19,20)$. The journal impact factors $\left(I F_{2019}\right)$ were taken from the Journal Citation Reports (JCR) published in 2019.

In the SCI-EXPANDED database, the corresponding author is designated as the "reprint" author; "corresponding author" will remain as the primary terminology instead of reprint author (21). In a single-author article where authorship is unspecified, the single author is considered both the first author and the corresponding author (22). Similarly, in an individually institutional article, the institution is both classified as the first institution and the corresponding institution (22). In cases of multiple corresponding authors, only the last corresponding author and their affiliation were considered (23). In cases of singleauthor articles, only the first affiliation and first country were considered.

Affiliations in England, Scotland, Northern Ireland, and Wales were reclassified as in the United Kingdom (UK) (24). Affiliations of authors in Hong Kong prior to 1997 were included under the heading of China (25). Affiliations in the Union of Soviet Socialist Republics (USSR) were checked and reclassified as in Russia and Ukraine (19). Similarly, USSR Academy of Medical Sciences (Acad Med Sci USSR) was also checked and re-classified under the heading of Russian Academy of Medical Sciences (Russian Acad Med Sci).

To investigate the citations received by the publications, we used four citation indicators:

* $\mathrm{C}_{0}$ : the the number of citations from the Web of Science Core Collection in publication year (26);

- $C_{\text {year }}$ : the number of citations from the Web of Science Core Collection in a particular year. $C_{2019}$ means the number of citations in 2019 (21); 
Table 1 Citations and authors according to document type

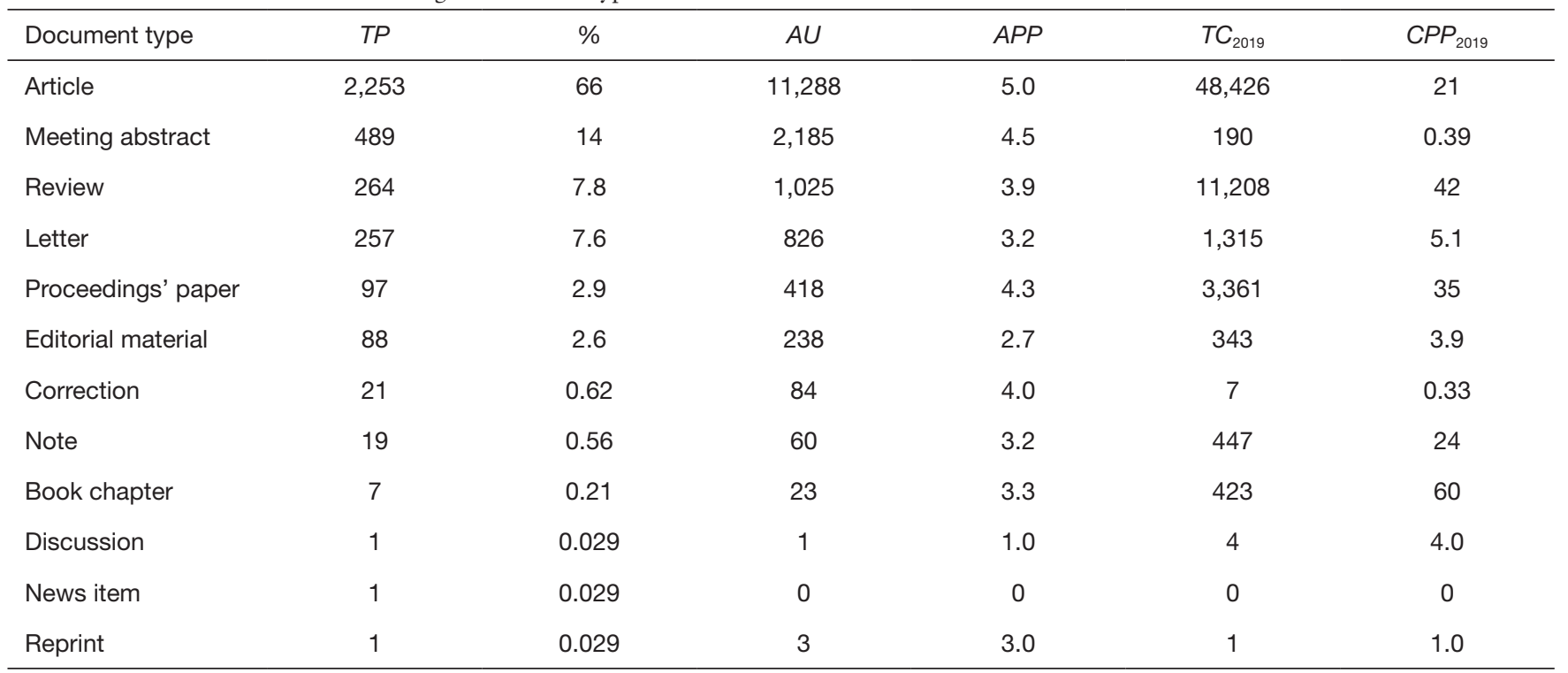

$T P$, number of publications; $A U$, number of authors; $A P P$, number of authors per publication; $T C_{2019}$, the total number of citations from Web of Science Core Collection since publication year to the end of 2019; $C P P_{2019}$, number of citations $\left(T C_{2019}\right)$ per publication (TP).

* $T C_{\text {year }}$ : the total number citations from the Web of Science Core Collection since publication to the end of the most recent year. In this study this is 2019 $\left(T C_{2019}\right)(8,27)$;

* $C P P_{\text {year }}$ : citations per publication $\left(C P P_{2019}=\right.$ $T C_{2019} / T P$ ) (21). TP indicates the total number of publications.

\section{Results and discussion}

\section{Characteristics of document types}

Document type characteristics with their citations per publication $\left(C P P_{\text {year }}=T C_{\text {year }} / T P\right)$ and number of authors per publication $(A P P=A U / T P)$ was recently suggested. The advantage of using $T C_{2019}$ for $C P P_{2019}$ is that they are invariable and ensure repeatability compared with the index of citation from Web of Science Core Collection (28). A total of 3,394 keloid related documents published in SCIEXPANDED were found among 12 document types. Table 1 shows characteristics of the 12 document types, including 2,253 articles (66\% of 3,394 documents) with number of authors per publication $(A P P)$ of 5.0 which was higher than other document types. The percentage of articles $(66 \%)$ was lower than other medical related topics, for example $79 \%$ in asthma in children (29), 75\% human papillomavirus (30), and $70 \%$ in Ebola (9) but similar to cisplatin-containing chemotherapy for small cell lung cancer (68\%) (31), acupuncture (66\%) (32).

A total of 489 meeting abstracts were published in 60 different journals but mainly focused on three journals: Fournal of Investigative Dermatology (115 meeting abstracts; $24 \%$ of 489 meeting abstracts) with a $C P P_{2019}$ of 0.30 , Wound Repair and Regeneration $(95 ; 19 \%)$ with a $C P P_{2019}$ of 1.3 , and Fournal of the American Academy of Dermatology (48; 10\%) with a $C P P_{2019}$ of 0.10 .

The document type of book chapters with seven documents had the greatest $C P P_{2019}$ value of 60 followed by reviews with a $C P P_{2019}$ of 42 . The $C P P_{2019}$ of document type of reviews was found to be double of articles. It should be pointed out that documents could be classified in two document types in Web of Science, for example, the highly cited document entitled "Basic components of connective tissues and extracellular matrix: Elastin, fibrillin, fibulins, fibrinogen, fibronectin, laminin, tenascins and thrombospondins" (33) was classified as "article" and "book chapter"; thus, the sum of percentages was higher than $100 \%$.

Only the 2,253 articles were selected for further analysis on the basis of containing whole research ideas and results (34). There were nine languages in use and one article was unspecified in SCI-EXPANDED. English, as the most popular language, comprised $94 \%$ of the 2,253 keloid articles. Other non-English languages 


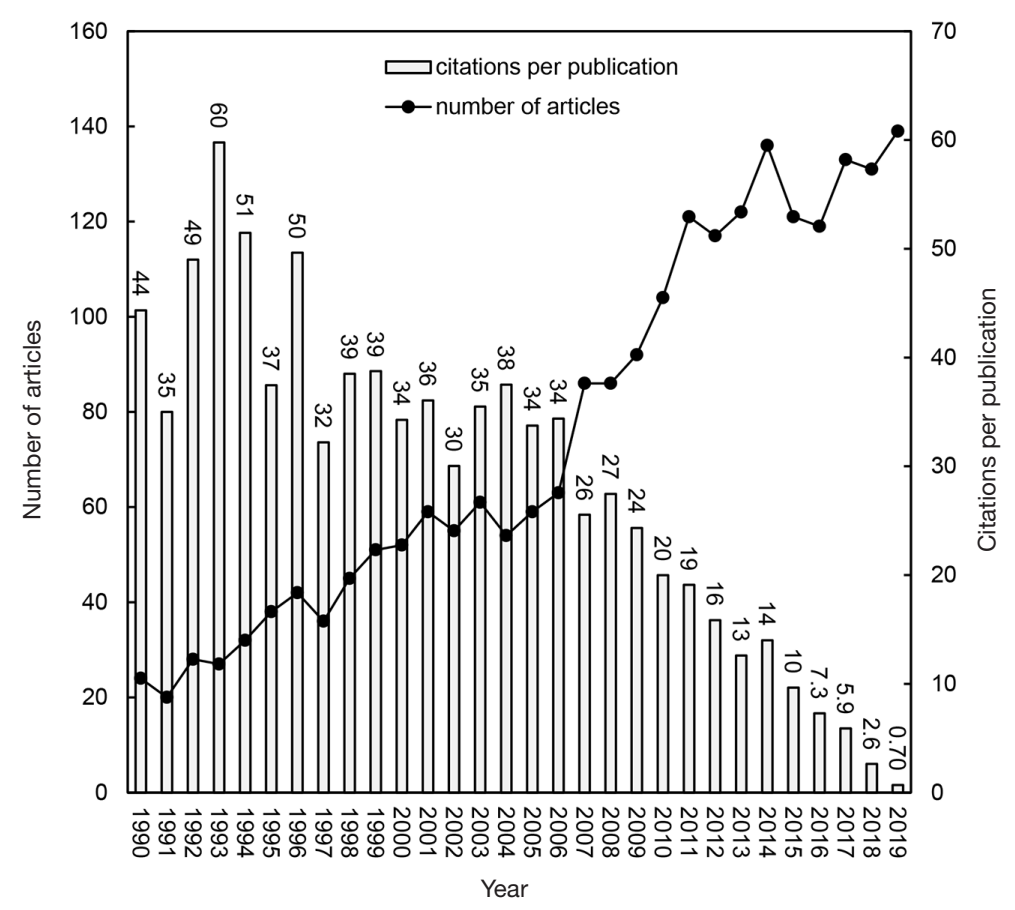

Figure 1 Number of keloid articles and citations per publication by year.

that were less used were listed as follows, German (41 articles), French (34), Chinese (6), Russian (5), Portuguese (3), Japanese (2), and one in each of Polish and Spanish, respectively.

\section{Characteristics of publication outputs}

The use of $T C_{2019}$ for determination of $C P P_{2019}$ is preferred as compared with the citation index from Web of Science Core Collection directly because they are consistent and ensure repeatability (35). In order to understand publications and their impact trends in a research field, Ho proposed a relationship between total number of articles $(T P)$ in a year and their citations per publication $\left(C P P_{\text {year }}\right.$ $=T C_{\text {year }} / T P$ ) by the decades (21) and years (31). In recent years, it has been applied in medical related topics, for example pain (8), Ebola (9), and dengue (10). A total of the 2,253 keloid related articles were published between 1990 and 2019. The mean value of $T C_{2019}$ was 21 with 492 as the maximal value for an article. Figure 1 demonstrated the distribution of the annual number of articles $(T P)$ and their citations per publication $\left(C P P_{2019}\right)$ by year, which was expressed as $T C_{2019} / T P(22)$, where $T P$ is number of articles published in that particular year. From 1990 through 2006, the annual number of articles increased from 24 in
1990 to 63 in 2006 and then sharply increasing to reach 139 in 2019.

\section{Web of science category and journal}

JCR indexed 9,381 journals with citation references across $178 \mathrm{Web}$ of Science categories in SCI-EXPANDED in 2019. In order to know development among research fields and their interactions, a relationship between the number of articles in categories and publication years was reported (34). The keloid related articles were published by 635 journals among the $98 \mathrm{Web}$ of Science categories in SCI-EXPANDED. A total of 1,348 articles $(60 \%$ of 2,253 articles) were published in the top two Web of Science categories: dermatology with 850 articles (38\% of 2,253 articles) and surgery with 722 articles (32\%). In 2019 , a total 68 journals and 210 journals were classified to categories of dermatology and surgery, respectively. Other top ten productive categories were research and experimental medicine (183 articles; $8.1 \%$ of 2,253 articles), cell biology (149; 6.6\%), pathology (128; 5.7\%), oncology (104; 4.6\%), biochemistry and molecular biology $(98 ; 4.3 \%)$, general and internal medicine $(85 ; 3.8 \%)$, otorhinolaryngology $(74 ; 3.3 \%)$, and pharmacology and pharmacy $(67 ; 3.0 \%)$. It has been noticed that journals 
Table 2 The top 11 most productive journals

\begin{tabular}{llllll}
\hline Journal & $T P(\%)$ & $I F_{2019}$ & $A P P$ & $C_{2019}$ & Web of Science category \\
\hline Dermatologic Surgery & $83(3.7)$ & 2.567 & 4.0 & 33 & Dermatology; surgery \\
Plastic and Reconstructive Surgery & $81(3.6)$ & 4.235 & 5.0 & 41 & Surgery \\
Annals of Plastic Surgery & $58(2.6)$ & 1.354 & 4.9 & 23 & Surgery \\
Journal of Investigative Dermatology & $56(2.5)$ & 7.143 & 7.1 & 50 & Dermatology \\
British Journal of Dermatology & $50(2.2)$ & 7.000 & 5.8 & 35 & Dermatology \\
Wound Repair and Regeneration & $48(2.1)$ & 2.471 & 5.8 & 30 & Cell biology; dermatology; research and \\
& & & & 16 & experimental medicine; surgery \\
International Journal of Dermatology & $40(1.8)$ & 2.067 & 4.3 & 22 & Dermatology \\
Archives of Dermatological Research & $39(1.7)$ & 2.339 & 5.6 & 2.6 & Dermatology \\
Experimental Dermatology & $32(1.4)$ & 3.368 & 6.1 & 19 & Surgery \\
Aesthetic Plastic Surgery & $30(1.3)$ & 1.798 & 4.2 & 18 & Critical care medicine; dermatology; surgery \\
Burns & $30(1.3)$ & 2.066 & 5.2 & 15 & \\
\hline
\end{tabular}

$T P$, number of articles; \%, the percentage of articles in total publications; $I F_{2019}$, journal impact factor in 2019 ; $A P P$, number of authors per publication; $C P P_{2019}$, number of citations $\left(T C_{2019}\right)$ per publication $(T P)$.

could be classified in two or more categories in Web of Science, for example Wound Repair and Regeneration was classified in the categories of cell biology, dermatology, research and experimental medicine, and surgery thus the sum of percentages was higher than $100 \%$ (22).

In total 2,253 keloid related articles were published in 635 journals including 565 were listed in SCIEXPANDED in 2019. The top 11 productive journals with 30 articles or more were listed in Table 2. Dermatologic Surgery $\left(I F_{2019}=2.567\right)$ published the most articles with 83 articles (3.7\% of 2,253 articles) followed by Plastic and Reconstructive Surgery $\left(I F_{2019}=4.235\right)$ with 81 articles (3.6\%). Compare the top 11 journals, keloid articles published in Fournal of Investigative Dermatology ( $I F_{2019}$ $=7.143)$ had the highest $C P P_{2019}$ of 50 while articles in Burns $\left(I F_{2019}=2.066\right)$ had a $C P P_{2019}$ of 15 . Articles published in Fournal of Investigative Dermatology also had the highest APP of 7.1 while articles in Dermatologic Surgery $\left(I F_{2019}=2.567\right)$ had an APP of 4.0. Eight of the top 11 journals were classified in the Web of Science category of dermatology, six in surgery, and one in each of cell biology, critical care medicine, and research and experimental medicine, respectively. Plastic and Reconstructive Surgery (81 articles; ranked $2^{\text {nd }}$ ) published the most six keloid articles in 2019. The journal with the highest $\mathrm{IF}_{2019}$ of 60.390 was Lancet followed by Science $\left(I F_{2019}=41.846\right)$ and Nature Genetics $\left(I F_{2019}=27.605\right)$ with one article, respectively.

\section{Publication performances: countries and institutions}

To compare publication performance of countries and institutions, Ho's group proposed six publication indicators such as total number of articles $(T P)$, singlecountry articles $(I P)$, internationally collaborative articles $(C P)$, first-author articles $(F P)$, corresponding-author articles $(R P)$, and single-author articles $(S P)(24,34,36)$. First author and corresponding author are the two most contributed authors in an article (37). At the institutional level, the determined institution of the correspondingauthor might be a home base of the study or origin of the paper (21). There were six articles without affiliations information in SCI-EXPANDED. Of 2,247 articles with author affiliations from 86 countries, 1,941 ( $86 \%$ of 2,247 articles) were single-country articles from 69 countries and $306(14 \%)$ were internationally collaborative articles from 61 countries. The top 15 productive countries/regions are listed in Table 3 with six publication indicators (36) and a citation indicator $\left(C P P_{2019}\right)$. The advantage of using $C P P_{2019}$ is that it is invariant in comparison with the index of citations from the Web of Science Core Collection which has to be updated from time to time (17). Seven Asian countries, five European countries, and three American countries were ranked on the top 15 of publications. USA ranked top in the six publication indicators with a $T P$ of 608 articles (27\% of 2,247 articles), an IP of 470 articles 
Table 3 Top 15 productive countries/regions with six publication indicators and their $C P P_{2019}$

\begin{tabular}{|c|c|c|c|c|c|c|c|c|}
\hline Countries/regions & $T P$ & TP R (\%) & IP R (\%) & $C P R(\%)$ & FP R (\%) & $R P R(\%)$ & $S P R(\%)$ & $C P P_{2019}$ \\
\hline China & 341 & $2(15)$ & $2(15)$ & $2(19)$ & $2(14)$ & $2(14)$ & $12(1.6)$ & 10 \\
\hline Japan & 202 & $3(9.0)$ & $3(8.4)$ & $5(13)$ & $3(8.1)$ & $3(8.1)$ & $5(3.9)$ & 29 \\
\hline Germany & 177 & $4(7.9)$ & $4(6.1)$ & $4(19)$ & $4(6.1)$ & $4(6.1)$ & $4(4.7)$ & 29 \\
\hline South Korea & 128 & $6(5.7)$ & $6(5.3)$ & $8(8.5)$ & $6(5.0)$ & $6(5.2)$ & $12(1.6)$ & 13 \\
\hline Italy & 95 & $7(4.2)$ & 7 (3.2) & $6(10)$ & $7(3.4)$ & $7(3.3)$ & $12(1.6)$ & 22 \\
\hline France & 70 & $8(3.1)$ & $9(2.8)$ & $12(4.9)$ & $10(2.6)$ & $9(2.7)$ & $8(2.3)$ & 24 \\
\hline Brazil & 66 & $9(2.9)$ & $10(2.8)$ & $14(3.9)$ & $9(2.6)$ & $10(2.6)$ & $19(0.78)$ & 16 \\
\hline Singapore & 56 & $12(2.5)$ & $15(1.5)$ & $8(8.5)$ & $12(2.0)$ & $14(2.1)$ & $12(1.6)$ & 32 \\
\hline Netherlands & 52 & $13(2.3)$ & $13(1.9)$ & $11(5.2)$ & $12(2.0)$ & $11(2.1)$ & $\mathrm{N} / \mathrm{A}$ & 22 \\
\hline Taiwan & 50 & $14(2.2)$ & $12(2.1)$ & $17(3.3)$ & $11(2.2)$ & $11(2.1)$ & $19(0.78)$ & 21 \\
\hline Turkey & 48 & $15(2.1)$ & $11(2.2)$ & $21(2.0)$ & $12(2.0)$ & $11(2.1)$ & $2(5.5)$ & 13 \\
\hline
\end{tabular}

$T P$, number of total articles; $I P$, single-country articles; $C P$, internationally collaborative articles; $F P$, first-author articles; $R P$, correspondingauthor articles, $S P$, single-author articles; $R$, rank; $C P P_{2019}$, number of citations $\left(T C_{2019}\right)$ per publication $(T P)$; N/A, not available.

(24\% of 1,941 single-country articles), a $C P$ of 138 articles ( $45 \%$ of 306 internationally collaborative articles), an $F P$ of 537 articles (24\% of 2,247 first-author articles), an $R P$ of 516 articles (24\% of 2,193 corresponding-author articles), and an $S P$ of 57 articles ( $45 \%$ of 128 single-author articles). Domination in keloid articles by the USA was not surprising since this pattern occurs in other medical topics: stem cells (38), obstetrics and gynecology (39), and orthopaedic surgery (40). USA also had the highest $C P P_{2019}$ of 34. China ranked second in the four publication indicators such as $T P, I P, C P, F P$, and $R P$ but had lower $C P P_{2019}$ of 10 . Among the 86 countries, 17 countries ( $20 \%$ of 86 countries) had no single-country articles while 25 countries (29\%) had no internationally collaborative articles. In addition, $9(10 \%), 13(15 \%)$, and $56(65 \%)$ countries have no first-author, correspondingauthor, and single-author articles, respectively. Figure 2 shows publication trends of the top six productive countries with 128 articles or more. Only China had a dramatic increase in annual number of articles since 2012. As for institutions, 925 keloid related articles (41\% of 2,247 articles) were of single-institution and 1,322 articles (59\%) were institutional collaborations. Table 4 demonstrates the characteristics of the top 15 productive institutions. Six of them were in USA, four in China, two in South Korea, and one in each of Japan, Singapore, and the UK, respectively. The University of Manchester in the UK took the leading position for four of the six publication indicators with a $T P$ of 56 articles (2.5\% of 2,247 articles), a $C P$ of 45 articles (3.4\% of 1,322 inter-institutionally collaborative articles), an $F P$ of 44 articles (2.0\% of 2,247 first-author articles), and an $R P$ of 42 articles (1.9\% of 2,193 corresponding-author articles) while the University of Miami in the USA ranked top in single-institution articles with an $I P$ of 17 articles (1.8\% of 925 single-institution articles). The St. Luke's-Roosevelt Hospital Center in the USA published 13 keloid articles (ranked 27th) including the most single-author articles with an $S P$ of five articles (3.9\% of 128 single-author articles). Compare the top 15 productive institutes, the Thomas Jefferson University in the USA had the highest $C P P_{2019}$ of 55. Articles published by the institutes in the USA had higher $C P P_{2019}$. However, four Chinese institutions including the Fourth Military Medical University, the Shanghai Jiao Tong University, the Peking Union Medical College, and the Chinese Academy of Medical Sciences had lower $C P P_{2019}$ of $16,7.5,7.4$, and 6.8 , respectively. 


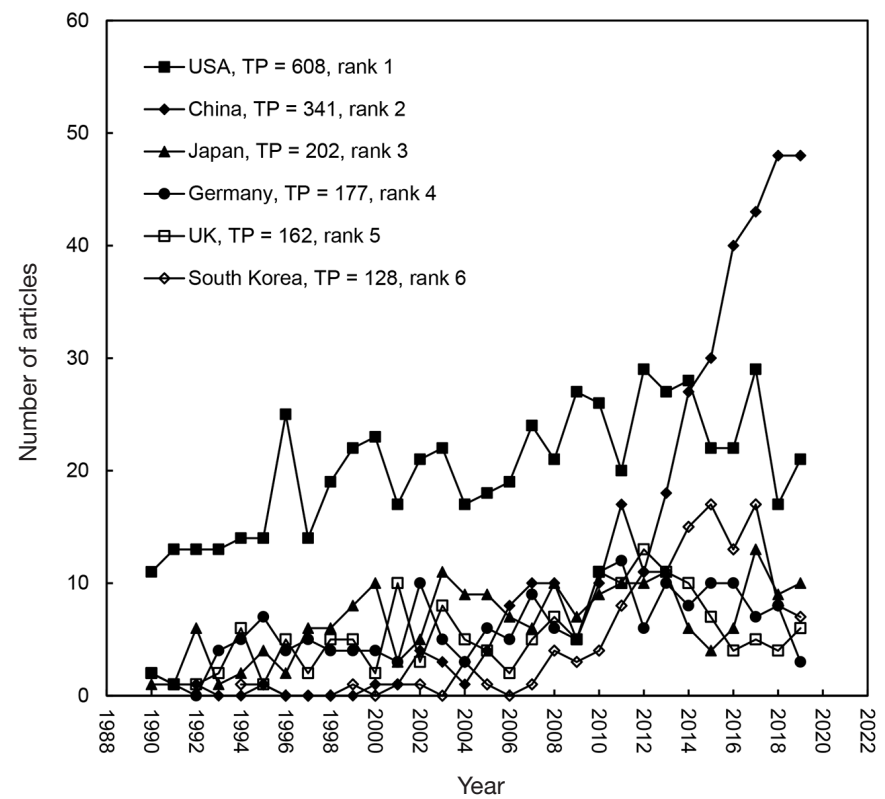

Figure 2 Comparison of the growth trends of the top six productive countries $(T P \geq 128)$.

Table 4 Top 15 productive institutions with six publication indicators and their $C P P_{2019}$

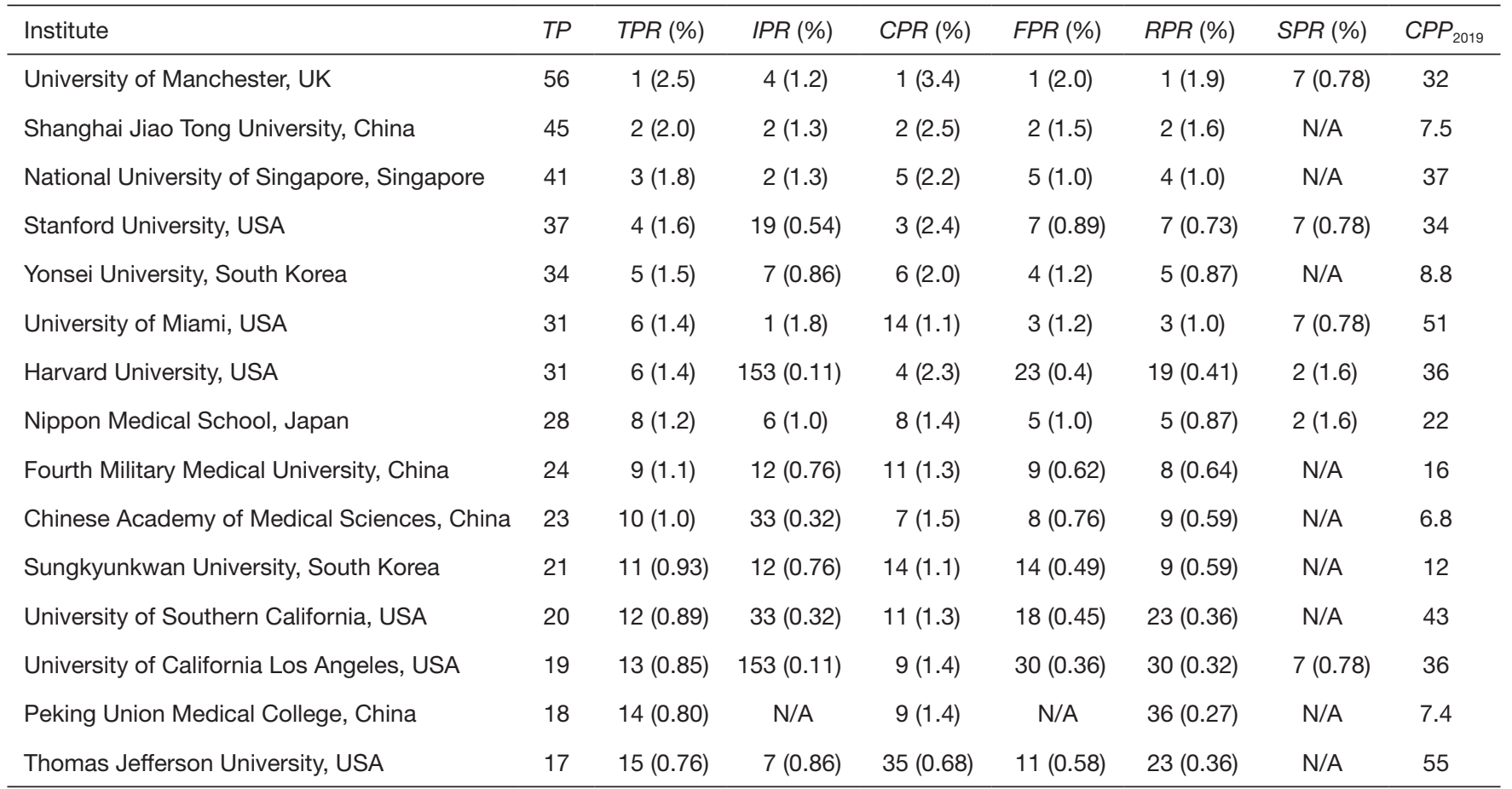

$T P$, total number of highly cited articles; TPR (\%), IPR (\%), CPR (\%), FPR (\%), RPR (\%), and SPR (\%), the rank and percentage of total articles, single-institution articles, inter-institutionally collaborative articles, first-author articles, corresponding-author articles, singleauthor articles in their total articles; $C P P_{2019}$, number of citations $\left(T C_{2019}\right)$ per publication $(T P)$; N/A, not available. 


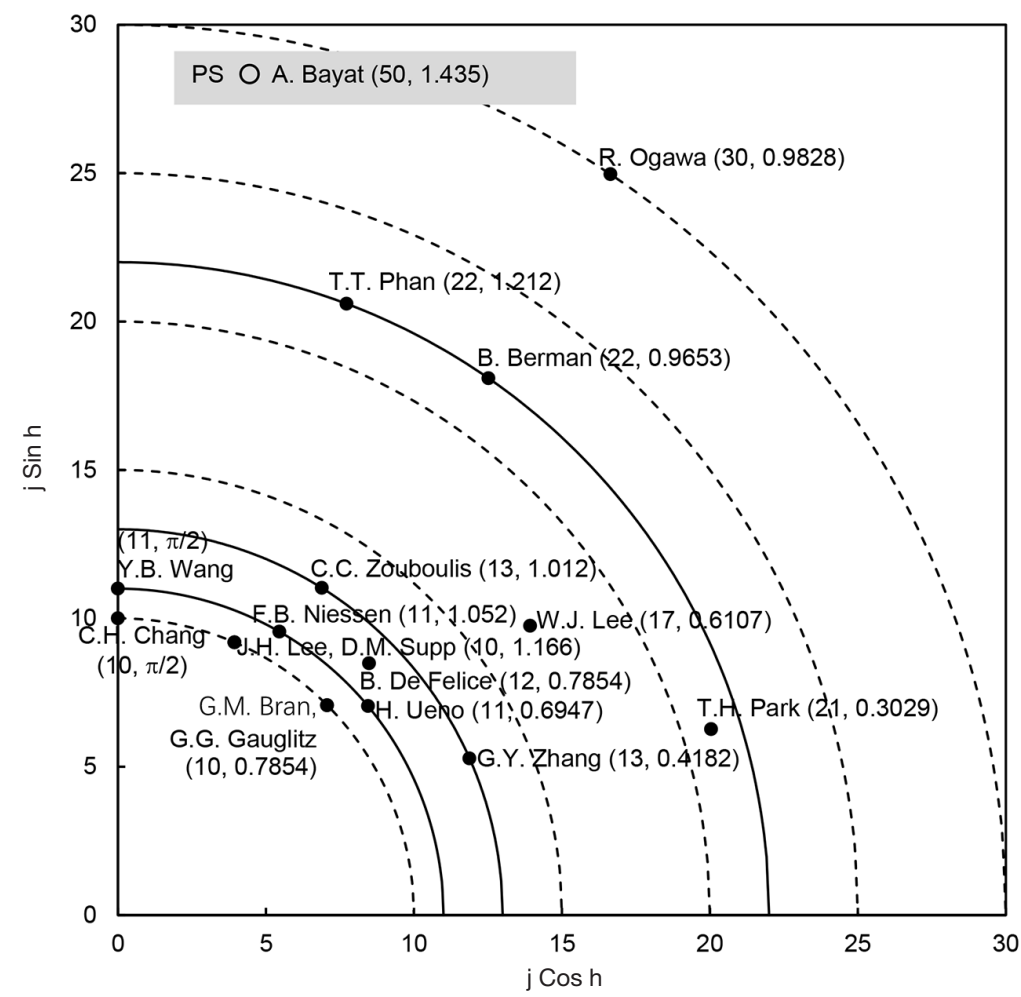

Figure 3 Top 17 authors with $Y$-index $(j \geq 10)$.

\section{Publication performances: autbors}

First and corresponding authors has the most contribution to the overall paper $(41,42)$. The $Y$-index was proposed in recent years $(21,22,26)$ to evaluate publication potential and characterize the scientific contributions by authors, institutions, and countries in relations to the numbers of first-author articles $(F P)$ and corresponding-author articles $(R P)$. The $Y$-index with two parameters $(j, b)$ can aid in visualization and comparison among different authors' contributions and is expressed as:

$$
\begin{aligned}
& j=F P+R P \\
& h=\tan ^{-1}\left(\frac{R P}{F P}\right)
\end{aligned}
$$

where $j$ is the publication potential, a constant related to publication quantity; and $b$ is publication characteristics which can describe the proportion of $R P$ to $F P$. The greater the value of $j$, the greater the number of firstand corresponding-author articles by the author. Different values of $b$ represent different proportions of corresponding-author articles from first-author articles.

* $b=\pi / 2, j$ is the number of corresponding-author articles;
* $\pi / 2>b>0.7854$ indicates more correspondingauthor articles;

* $b=0.7854$ indicates the same number of first- and corresponding-author articles;

* $0.7854>b>0$ indicates more first-author articles;

- $b=0, j$ is the number of first-author articles.

In total of 2,163 keloid articles (96\% of 2,253 articles) with both first- and corresponding-authors information in SCI-EXPANDED were extensively analysed by using the $Y$-index. Figure 3 demonstrated the distribution of the $Y$-index $(j, b)$ of the top 17 potential authors with $j \geq 10$. Each point has a coordinate $(j, b)$ that could symbolize a single author or multiple authors (22). A. Bayat $(50,1.435)$ published 52 articles including six first-author articles and 44 corresponding-author with $j$ value of 50 which is far away from the original (not in Figure 3). Bayat had the highest publication potential in keloid research (43). Some authors are located on the same curve (for example, $j=11$ ), indicating that they had the same publication potential but different publication characteristics (35). It has been pointed out that with these data has a potential for bias in the analysis of authorship; it might attribute to different authors having the same name, or the same 


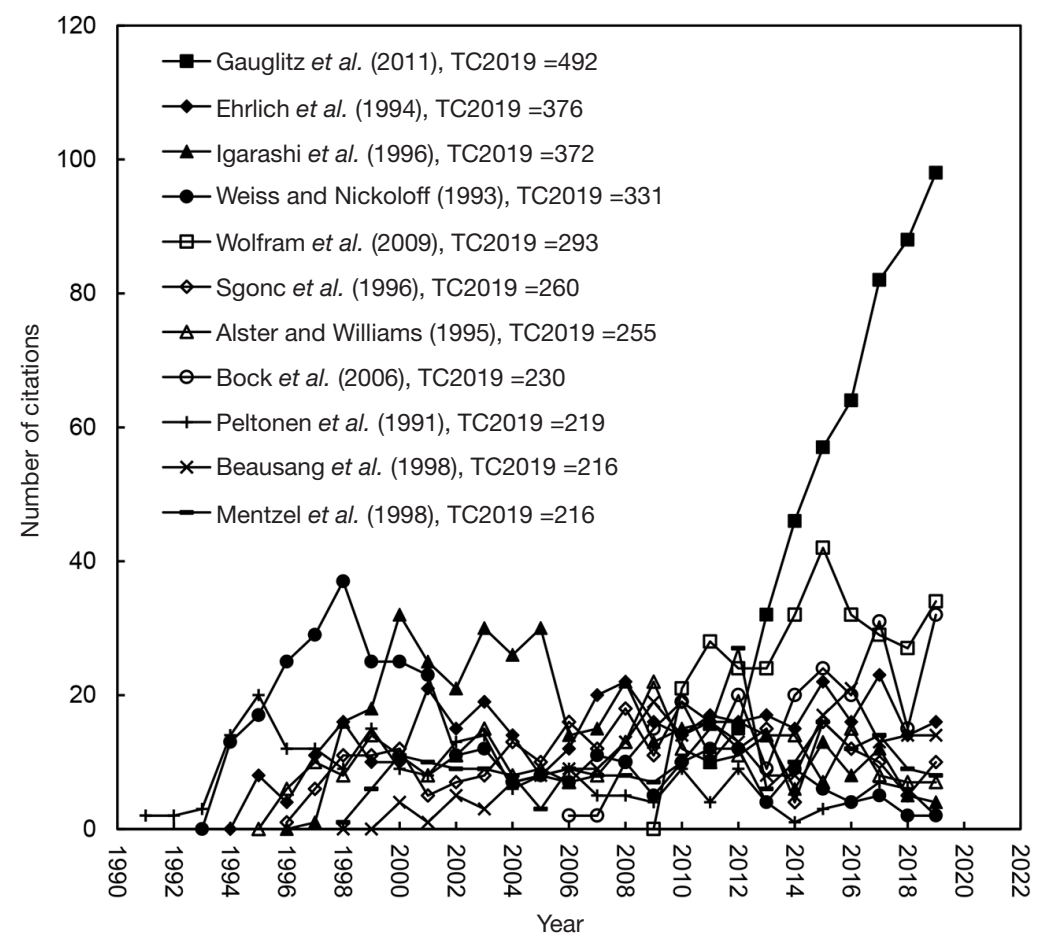

Figure 4 The citation histories of the 11 highly cited keloid articles with $T C_{2019} \geq 216$.

author using different names over time (28). Another potential confounder arises when an author moves from one affiliation to another (44).

\section{Citation histories of the 11 most frequently cited articles}

Information of total citations from Web of Science Core Collection was updated weekly. To improve bibliometric study, the total number of citations from Web of Science Core Collection since publication year to the end of 2019 $\left(T C_{2019}\right)$ was applied to improve the bias using data from Web of Science directly. The advantage of $T C_{2019}$ is that they are invariable and ensure repeatability compared with the citation index from Web of Science Core Collection (17). The citation histories of the top 11 most frequently cited keloid articles $\left(T C_{2019} \geq 216\right)$ are shown in Figure 4. Eight of the top 11 articles published in the 1990s, which had a longer impact history, but less impact in the recent years.

"Green Giants" are articles have sharply increasing citations after publication for some years compared with others in the same field, and they quickly become high impact publications in recent year with a high $C_{\text {year }}$, which is more than double compare with others (45).
Article entitled "Hypertrophic scarring and keloids: Pathomechanisms and current and emerging treatment strategies" (46) was the only "Green Giant" in keloid studies, which ranked top in $C_{2019}$ of 98 which is much higher than any others. Figure 4 shows the "Green Giant" in keloid studies had sharply increasing citation rates for eight full years after its publication. "Green Giants" can be also found in other research fields, for example category of environmental sciences (47), pain research (8), and publications in Taiwan (45).

\section{Citation histories of the ten most impact articles in 2019}

The amount of citation received in the year $2019\left(C_{2019}\right)$ and in the publication year $\left(C_{0}\right)$ might provide additional information for readers to understand the impact of a highly cited article today versus its immediate effect post publication (21). The 2,253 keloid related articles ranked differently if sorted by $T C_{2019}, C_{2019}$ than sorted by $C_{0}$. A total of 836 articles ( $37 \%$ of 2,253 articles) had no citation in the most recent year of $2019\left(C_{2019}=0\right)$ and $1,793(80 \%)$ articles had no citation in the initial publication year $\left(C_{0}=0\right)$. Furthermore, among the top $100 C_{0}$ articles, only $9.4 \%$ and $23 \%$ of the articles were 


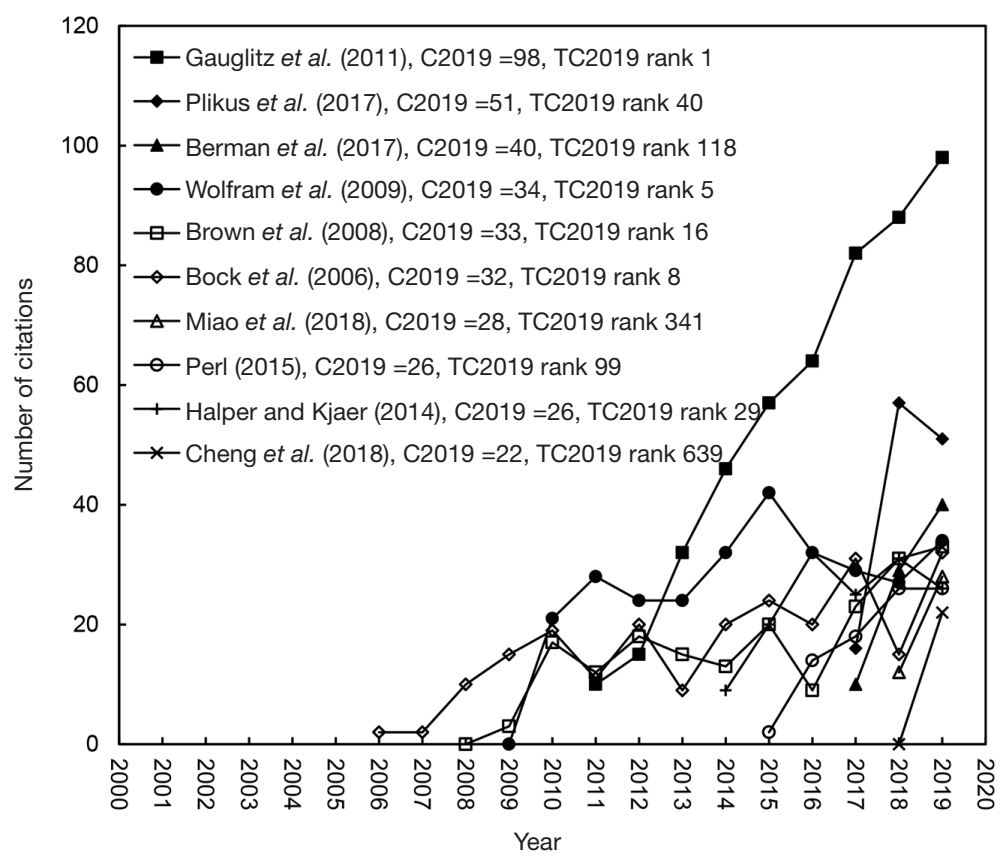

Figure 5 The citation histories of the 10 most impact keloid articles in 2019 with $C_{2019} 22$.

among the top $100 T C_{2019}$ and $C_{2019}$ articles, respectively. The percentages were found different from research topics: occupational therapy (12\% and 13\%) (48) and metal-organic frameworks (22\% and 24\%) (19). Top ten most impact keloid articles in 2019 with $C_{2019} \geq 22$ and their citation history trends are outlined in Figure 5. Articles by Gauglitz et al. (46), Wolfram et al. (49), and Bock et al. (50) ranked not only the top ten in $C_{2019}$ but also the top ten in $T C_{2019}$. Since the recent articles had a shorter article life and a shorter time to accumulate citations, the high impact articles in 2019 published by Cheng et al. (51), Miao et al. (52), and Berman et al. (53) had a $T C_{2019}$ of $22\left(\right.$ rank $\left.639^{\text {th }}\right), 40\left(\right.$ rank $\left.341^{\text {th }}\right)$, and 79 $\left(\right.$ rank $\left.118^{\text {th }}\right)$, respectively. Article entitled "Regeneration of fat cells from myofibroblasts during wound healing" published in Science had a sharply increasing trend after publication in 2017 (54).

\section{Research focuses and development trends from 1990 to 2019}

Ho's group proposed the distribution of words in article titles, abstracts, author keywords, and KeyWords Plus in different periods as information to evaluate the main research focuses and determine their development trends in research topics $(27,55)$. In this study, the distribution of single words in article titles was analyzed because the title of an article always best summarizes the main idea of the study. After eliminating empty words such as "a" and "the", the 20 most frequently used single words in titles are presented in Table 5. Their occurrence times were calculated in the 30-year period and three decades (1990-1999, 2000-2009, and 2010-2019).

Further, word cluster analysis with noun phrases in title, abstract, author keywords, and KeyWords Plus compensates for the weakness of single word distribution analysis (27). Noun phrases were generated from the sources above using the LLR algorithm and imported to MapEquation to generate an alluvial diagram that vividly demonstrated how research hotspots changed over time (56). The alluvial diagram shows the progression of research hotspots in keloids (Figure 6). Each column represents a cluster. The height of the column indicates the sum of the page rank value of all noun phrases in a cluster. The page rank values of each noun phrase indicates its importance.

First, there is an emerging trend in the underlying pathogenetic mechanisms of keloids. Supporting words in title included "fibroblasts", "expression”, "collagen", "formation", and "proliferation". Particularly, the frequency of "fibroblasts" and "expression" increased from rank 6 and 7 in the first decade to 4 and 6 in the last decade, 
Table 5 Top 20 most frequently used substantives in title during the past three decades

\begin{tabular}{|c|c|c|c|c|c|}
\hline Words in title & $T P$ & \multicolumn{4}{|c|}{ Rank (\%) } \\
\hline Keloid & 768 & $1(34)$ & $1(27)$ & $1(30)$ & $1(38)$ \\
\hline Keloids & 465 & $2(21)$ & $2(22)$ & $2(22)$ & 2 (19) \\
\hline Treatment & 347 & $3(15)$ & $4(16)$ & $4(13)$ & $3(16)$ \\
\hline Scars & 300 & $5(13)$ & $3(16)$ & $5(12)$ & $5(13)$ \\
\hline Hypertrophic & 228 & $6(10)$ & $4(16)$ & $6(12)$ & $9(7.7)$ \\
\hline Expression & 200 & $7(8.9)$ & $11(6.4)$ & $7(10)$ & $6(9.2)$ \\
\hline Skin & 181 & $8(8)$ & $8(7.6)$ & $8(7.8)$ & $8(8.3)$ \\
\hline Human & 138 & $11(6.1)$ & $10(6.7)$ & $11(5.4)$ & $10(6.4)$ \\
\hline Growth & 122 & $12(5.4)$ & $17(3.2)$ & $9(6.9)$ & $12(5.2)$ \\
\hline Therapy & 97 & $13(4.3)$ & $28(2.3)$ & $21(3.6)$ & $12(5.2)$ \\
\hline Laser & 88 & $14(3.9)$ & $33(2)$ & $21(3.6)$ & $14(4.6)$ \\
\hline Intralesional & 87 & $15(3.9)$ & $20(2.9)$ & $16(3.7)$ & $15(4.2)$ \\
\hline Surgical & 86 & $16(3.8)$ & $33(2)$ & $13(4.2)$ & $16(4.1)$ \\
\hline Clinical & 83 & $17(3.7)$ & $33(2)$ & $15(4)$ & $18(3.9)$ \\
\hline Patients & 83 & $17(3.7)$ & $14(3.5)$ & $16(3.7)$ & $22(3.7)$ \\
\hline
\end{tabular}

TP, occurrence times of substantives in title during 1990 to 2019.

respectively. The word "proliferation" soared from rank 45 to 16 (Table 5). Thus, researchers tend to focus more on the pathogenetic mechanism in the molecular level, which can be cross-verified by cluster "keloid fibroblasts", "molecular mechanism", "protein expression", and "connective tissue growth factor" in Figure 6. It has been demonstrated that keloid fibroblasts and myofibroblasts originate from activated resident skin fibroblasts that interact with other cells including multiple types of immune cells and keratinocytes via signaling molecules such as matrix metalloproteinases, interleukins and cytokines (57). One important difference between keloid and normal fibroblasts is the overexpression of the TGF- $\beta$ signaling cascade (46). The TGF- $\beta$ signaling pathway not only plays a critical role in the fibroproliferative process leading to extracellular matrix accumulation (58) but also has a crosstalk with the mitogen-activated protein kinase (MAPK) pathway (59). The crosstalk is assumed to be associated with the invasiveness of keloid fibroblasts and, the MAPK pathway might be a specific target of keloid therapy (60). Other signaling pathways, including insulin-like growth factor-I and integrin pathways, have also been found to be activated in keloid fibroblasts $(61,62)$.

Second, increasingly more research attention has focused on keloid treatment. For example, the word "treatment" ranks top 4 in every decade, and the word "therapy" shifted dramatically from rank 28 in the first decade to 12 in the third decade. Other words related to treatment modalities including "laser", "intralesional" and "surgical" all soared during the 30-year period (Table 5). Keloid treatment has always been the focus of dermatologists and plastic surgeons. As single treatment also fails to result in a consistently low 


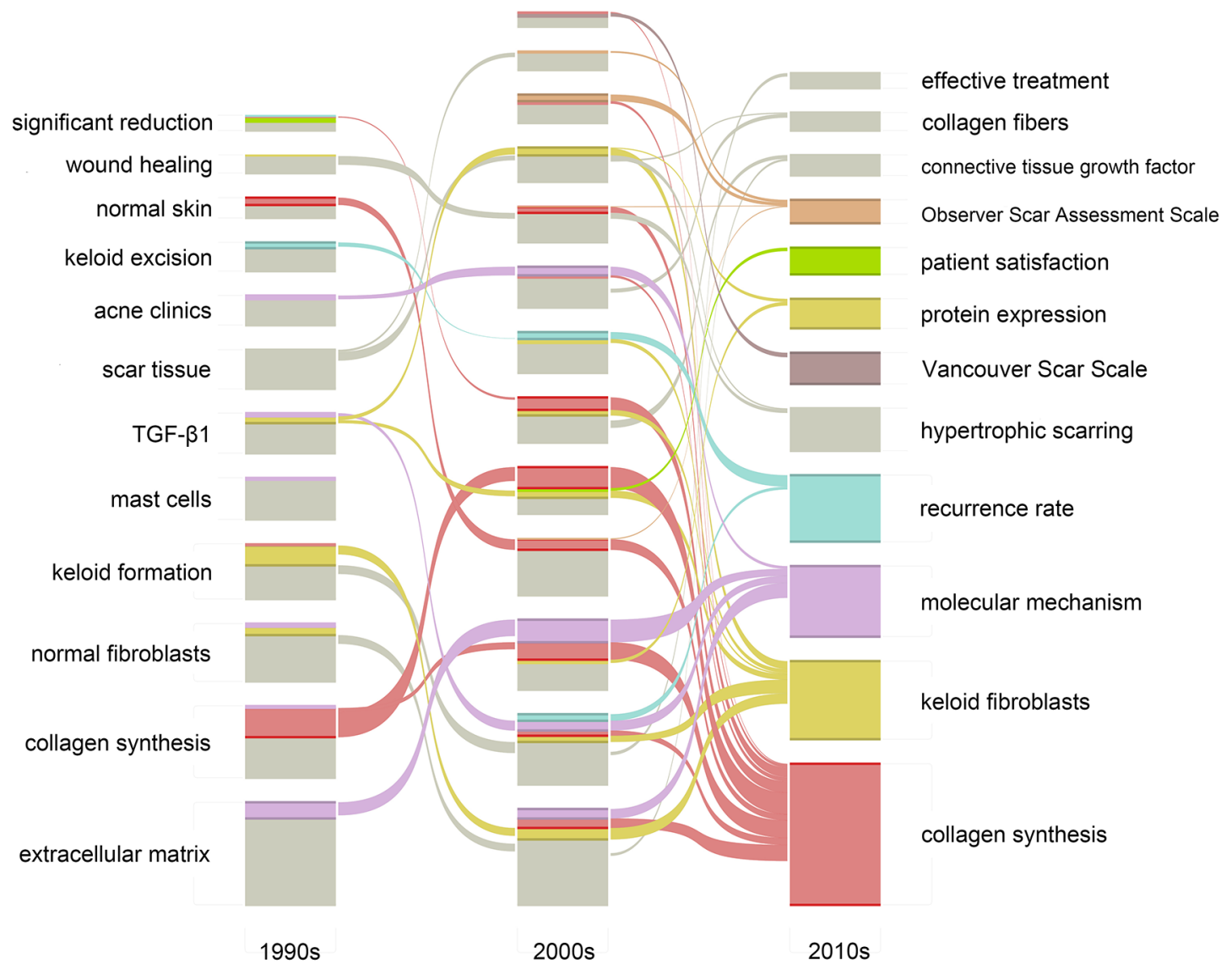

Figure 6 The progression of research hotspots in the recent three decades.

recurrence rate, increasingly more studies have focused on combination therapy, and it has been reported as the most efficacious and safe management for keloids (63). One common combination is laser therapy and triamcinolone acetonide (TAC) administration. Carbon dioxide laser $(64,65)$, pulsed dye laser with 5-fluorouracil (66), and neodymiumdoped yttrium garnet laser (67) yielded good results in combination with TAC. In addition to laser therapy with TAC administration, a low recurrence rate is achieved when surgical excision is combined with other treatment modalities, such as TAC, 5-Fluorouracil, pressure therapy, silicone gel, electron beam, and radiation therapy (68). Although there are already many treatment modalities, no gold standard for keloid treatment has been established, and many efforts are being made in the exploration of new therapies (69).

Lastly, researchers tend to be more comprehensive and objective in the evaluation of therapeutic effects. Supporting evidence includes cluster "recurrence rate", "Vancouver Scar Scale", "patient satisfaction", and "Observer Scar
Assessment Scale" (Figure 6). The Vancouver Scar Scale and Patient and Observer Scar Assessment Scale are two commonly used scales in patients with keloids $(70,71)$. These scales help clinicians and patients gain a comprehensive understanding of treatment responses and guide future treatment. Standardized scales also make the evaluation more comparable, allowing analysis across different studies. However, it should be acknowledged that scales provide quantitative but subjective assessments of therapeutic effects. The scale scores are subjected to a number of human factors, and it is also unclear whether the scale scores correlate with the underlying molecular profile of scars. Thus, objective scar assessment tools should be advocated in practicing evidence-based medicine. Verhaegen et al. reviewed noninvasive objective measurement tools to assess different scar features, including color, thickness, relief, pliability, and surface area (72). It is foreseeable that objective measurement tools will have a higher status in the assessment of keloids and scars. 


\section{Limitations}

Several limitations of this study should be addressed. First, the main body of this study only includes peer-reviewed original articles, which are the only document type that provides new findings and innovative insights supported by scientific proofs. The absence of other document types might result in the omission of some information. Second, it should be mentioned that citation numbers do not necessarily link with research quality. The citation number is determined by many factors, including research quality, self-citation, and citations from one's coworkers or the same institution. Finally, publication is a complex and time-consuming process. Bibliometric analysis based on publications is more like a summary of the past and is unable to identify the most up-to-date findings and treatment modalities.

\section{Conclusions}

This bibliometric analysis quantitatively studies the scientific landscape and research trends in keloid publications. We presented bibliometric data on document type, annual publication number, most productive journals, publication geography, top potential authors, and highly cited articles. Additionally, research trends were analyzed through single word analysis in title and noun-phrase co-occurrence analysis. Keloids have remained a research focus. Recent research hotspots include underlying pathogenetic mechanisms, keloid treatment, and therapeutic effect evaluation.

\section{Acknowledgments}

Funding: None.

\section{Footnote}

Reporting Checklist: The authors have completed the PRISMA reporting checklist. Available at http://dx.doi. org/10.21037/atm-21-508

Conflicts of Interest: All authors have completed the ICMJE uniform disclosure form (available at http://dx.doi. org/10.21037/atm-21-508). The authors have no conflicts of interest to declare.

Ethical Statement: The authors are accountable for all aspects of the work in ensuring that questions related to the accuracy or integrity of any part of the work are appropriately investigated and resolved.

Open Access Statement: This is an Open Access article distributed in accordance with the Creative Commons Attribution-NonCommercial-NoDerivs 4.0 International License (CC BY-NC-ND 4.0), which permits the noncommercial replication and distribution of the article with the strict proviso that no changes or edits are made and the original work is properly cited (including links to both the formal publication through the relevant DOI and the license). See: https://creativecommons.org/licenses/by-nc-nd/4.0/.

\section{References}

1. Ehrlich HP, Desmoulière A, Diegelmann RF, et al. Morphological and immunochemical differences between keloid and hypertrophic scar. Am J Pathol 1994;145:105-13.

2. Blackburn WR, Cosman B. Histologic basis of keloid and hypertrophic scar differentiation: Clinicopathologic correlation. Arch Pathol 1966;82:65-71.

3. Nakaoka H, Miyauchi S, Miki Y. Proliferating activity of dermal fibroblasts in keloids and hypertrophic scars. Acta Derm Venereol 1995;75:102-4.

4. Ueda K, Furuya E, Yasuda Y, et al. Keloids have continuous high metabolic activity. Plast Reconstr Surg 1999;104:694-8.

5. Younai S, Venters G, Vu S, et al. Role of Growth Factors in Scar Contraction. Ann Plast Surg 1996;36:495-501.

6. Murray JC. Keloids and hypertrophic scars. Clin Dermatol 1994;12:27-37.

7. Durani P, Bayat A. Levels of evidence for the treatment of keloid disease. J Plast Reconstr Aesthet Surg 2008;61:4-17.

8. Chuang KY, Ho YS. A bibliometric analysis on top-cited articles in pain research. Pain Med 2014;15:732-44.

9. Pouris A, Ho YS. A bibliometric analysis of research on Ebola in Science Citation Index Expanded. S Afr J Sci 2016;112:83-8.

10. Ho YS, Siu E, Chuang KY. A bibliometric analysis of dengue-related publications in the Science Citation Index Expanded. Future Virol 2016;11:631-48.

11. Rosas SR, Kagan JM, Schouten JT, et al. Evaluating research and impact: a bibliometric analysis of research by the NIH/NIAID HIV/AIDS clinical trials networks. PLoS One 2011;6:e17428.

12. Head MG, Fitchett JR, Newell ML, et al. Mapping pneumonia research: A systematic analysis of UK investments and published outputs 1997-2013. EBioMedicine 2015;2:1193-9.

13. Ho YS. Rebuttal to: Su et al. "The neurotoxicity of nanoparticles: A bibliometric analysis". Toxicol Ind Health 
2019;35:399-402.

14. Ho YS. Critical comment on: Zhu, Jin, and He 'On evolutionary economic geography: a literature review using bibliometric analysis', European Planning Studies vol. 27, pp 639-660. European Planning Studies 2019;27:1235-7.

15. Garfield E. KeyWords Plus: ISI's breakthrough retrieval method. Part 1. Expanding your searching power on Current Contents on Diskette. Curr Contents 1990;32:5-9.

16. Fu HZ, Ho YS. Top cited articles in thermodynamic research. Journal of Engineering Thermophysics 2015;24:68-85.

17. Fu HZ, Wang MH, Ho YS. The most frequently cited adsorption research articles in the Science Citation Index (Expanded). J Colloid Interface Sci 2012;379:148-56.

18. Fu HZ, Ho YS. Top cited articles in adsorption research using Y-index. Res Evaluat 2014;23:12-20.

19. Ho YS, Fu HZ. Mapping of metal-organic frameworks publications: A bibliometric analysis. Inorg Chem Commun 2016;73:174-82.

20. Li Z, Ho YS. Use of citation per publication as an indicator to evaluate contingent valuation research. Scientometrics 2008;75:97-110.

21. Ho YS. Top-cited Articles in Chemical Engineering in Science Citation Index Expanded: A Bibliometric Analysis. Chinese J Chem Eng 2012;20:478-88.

22. Ho YS. Classic articles on social work field in Social Science Citation Index: A bibliometric analysis. Scientometrics 2014;98:137-55.

23. Ho YS. Bibliometric Analysis of the Journal of Orthopaedic Research from 1991 To 2018. Ortho Res Online J 2019;6. doi: 10.31031/OPROJ.2019.06.000632.

24. Chiu WT, Ho YS. Bibliometric analysis of homeopathy research during the period of 1991 to 2003. Scientometrics 2005;63:3-23.

25. Fu HZ, Ho YS. Comparison of independent research of China's top universities using bibliometric indicators. Scientometrics 2013;96:259-76.

26. Ho YS. A bibliometric analysis of highly cited articles in materials science. Curr Sci 2014;107:1565-72.

27. Wang CC, Ho YS. Research trend of metal-organic frameworks: a bibliometric analysis. Scientometrics 2016;109:481-513.

28. Ho YS, Hartley J. Classic articles in Psychology in the Science Citation Index Expanded: A bibliometric analysis. Br J Psychol 2016;107:768-80.

29. Chen SR, Chiu WT, Ho YS. Asthma in children: mapping the literature by bibliometric analysis. Rev Fr Allergol Immunol Clin 2005;45:442-6.

30. Lin HW, Yu TC, Ho YS. A systemic review of human papillomavirus studies: global publication comparison and research trend analyses from 1993 to 2008. Eur J Gynaecol Oncol 2011;32:133-40.

31. Ho YS. The top-cited research works in the Science Citation Index Expanded. Scientometrics 2013;94:1297-312.

32. Han JS, Ho YS. Global trends and performances of acupuncture research. Neurosci Biobehav Rev 2011;35:680-7.

33. Halper J, Kjaer M. Basic components of connective tissues and extracellular matrix: Elastin, fibrillin, fibulins, fibrinogen, fibronectin, laminin, tenascins and thrombospondins. Adv Exp Med Biol 2014;802:31-47.

34. Ho YS, Satoh H, Lin SY. Japanese lung cancer research trends and performance in Science Citation Index. Intern Med 2010;49:2219-28.

35. Ho YS, Hartley J. Classic articles published by American scientists (1900-2014): a bibliometric analysis. Curr Sci 2016;111:1156-65.

36. Ho YS, Kahn M. A bibliometric study of highly cited reviews in the Science Citation Index expanded. J Assoc Inf Sci Tech 2014;65.

37. Riesenberg D, Lundberg GD. The Order of Authorship: Who's on First? JAMA 1990;264:1857.

38. Li LL, Ding GH, Feng N, et al. Global stem cell research trend: Bibliometric analysis as a tool for mapping of trends from 1991 to 2006. Scientometrics 2009.

39. Brandt JS, Downing AC, Howard DL, et al. Citation classics in obstetrics and gynecology: the 100 most frequently cited journal articles in the last 50 years. Am J Obstet Gynecol 2010;203:355.e1-7.

40. Kelly JC, Glynn RW, O'Briain DE, et al. The 100 classic papers of orthopaedic surgery: a bibliometric analysis. J Bone Joint Surg Br 2010;92:1338-43.

41. Gaeta TJ. Authorship: "Law" and order. Acad Emerg Med 1999;6:297-301.

42. Mattsson P, Sundberg CJ, Laget P. Is correspondence reflected in the author position? A bibliometric study of the relation between corresponding author and byline position. Scientometrics 2011;87:99-105.

43. Burman KD. "Hanging from the Masthead": Reflections on Authorship. Ann Intern Med 1982;97:602-5.

44. MacRoberts MH, MacRoberts BR. Problems of citation analysis: A critical review. J Am Soc Inf Sci Tec 1989;40:342-9.

45. Ho YS. Classic papers published by Taiwanese scientists in the science citation index expanded: A bibliometric study. COLLNET Journal of Scientometrics and Information Management 2018;12:83-95.

46. Gauglitz GG, Korting HC, Pavicic T, et al. Hypertrophic scarring and keloids: pathomechanisms and current and 
emerging treatment strategies. Mol Med 2011;17:113-25.

47. Khan MA, Ho YS. Top-cited articles in environmental sciences: Merits and demerits of citation analysis. Sci Total Environ 2012;431:122-7.

48. Brown T, Gutman SA, Ho YS, et al. A bibliometric analysis of occupational therapy publications. Scand J Occup Ther 2018;25:1-14.

49. Wolfram D, Tzankov A, Pulzl P, et al. Hypertrophic scars and keloids--a review of their pathophysiology, risk factors, and therapeutic management. Dermatol Surg 2009;35:171-81.

50. Bock O, Schmid-Ott G, Malewski P, et al. Quality of life of patients with keloid and hypertrophic scarring. Arch Dermatol Res 2006;297:433-8.

51. Cheng P, Zhang J, Huang J, et al. Near-infrared fluorescence probes to detect reactive oxygen species for keloid diagnosis. Chem Sci 2018;9:6340-7.

52. Miao Q, Yeo DC, Wiraja C, et al. Near-Infrared Fluorescent Molecular Probe for Sensitive Imaging of Keloid. Angew Chem Int Ed Engl 2018;57:1256-60.

53. Berman B, Maderal A, Raphael B. Keloids and Hypertrophic Scars: Pathophysiology, Classification, and Treatment. Dermatol Surg 2017;43 Suppl 1:S3-18.

54. Plikus MV, Guerrero-Juarez CF, Ito M, et al. Regeneration of fat cells from myofibroblasts during wound healing. Science 2017;355:748-52.

55. Mao N, Wang MH, Ho YS. A bibliometric study of the trend in articles related to risk assessment published inscience citation index. Hum Ecol Risk Assess 2010;16:801-24.

56. Rosvall M, Bergstrom CT. Mapping Change in Large Networks. PLoS One 2010;5:e8694.

57. Macarak EJ, Wermuth PJ, Rosenbloom J, et al. Keloid disorder: Fibroblast differentiation and gene expression profile in fibrotic skin diseases. Exp Dermatol 2021;30:132-45.

58. Jagadeesan J, Bayat A. Transforming growth factor beta (TGFbeta) and keloid disease. Int J Surg 2007;5:278-85.

59. Unahabhokha T, Sucontphunt A, Nimmannit U, et al. Molecular signalings in keloid disease and current therapeutic approaches from natural based compounds. Pharm Biol 2015;53:457-63.

60. He S, Liu X, Yang Y, et al. Mechanisms of transforming growth factor beta(1)/Smad signalling mediated by mitogen-activated protein kinase pathways in keloid

Cite this article as: Chong Y, Long X, Ho YS. Scientific landscape and trend analysis of keloid research: a 30-year bibliometric review. Ann Transl Med 2021;9(11):945. doi: 10.21037/atm-21-508 fibroblasts. Br J Dermatol 2010;162:538-46.

61. Daian T, Ohtsuru A, Rogounovitch T, et al. Insulin-like growth factor-I enhances transforming growth factor-betainduced extracellular matrix protein production through the P38/activating transcription factor-2 signaling pathway in keloid fibroblasts. J Invest Dermatol 2003;120:956-62.

62. Liu S, Xu SW, Blumbach K, et al. Expression of integrin beta1 by fibroblasts is required for tissue repair in vivo. $\mathrm{J}$ Cell Sci 2010;123:3674-82.

63. Al-Attar A, Mess S, Thomassen JM, et al. Keloid Pathogenesis and Treatment. Plast Reconstr Surg 2006;117:286-300.

64. Behera B, Kumari R, Thappa DM, et al. Therapeutic efficacy of intralesional steroid with carbon dioxide laser versus with cryotherapy in treatment of keloids: a randomized controlled trial. Dermatol Surg 2016;42:1188-98.

65. Wang J, Wu J, Xu M, et al. Combination therapy of refractory keloid with ultrapulse fractional carbon dioxide (CO2 ) laser and topical triamcinolone in Asians-longterm prevention of keloid recurrence. Dermatol Ther 2020;33:e14359.

66. Asilian A, Darougheh A, Shariati F. New combination of triamcinolone, 5-Fluorouracil, and pulsed-dye laser for treatment of keloid and hypertrophic scars. Dermatol Surg 2006;32:907-15.

67. Rossi A, Lu R, Frey MK, et al. The use of the 300 microsecond $1064 \mathrm{~nm} \mathrm{Nd:YAG} \mathrm{laser} \mathrm{in} \mathrm{the} \mathrm{treatment} \mathrm{of}$ keloids. J Drugs Dermatol 2013;12:1256-62.

68. Limmer EE, Glass DA, 2nd. A Review of Current Keloid Management: Mainstay Monotherapies and Emerging Approaches. Dermatol Ther (Heidelb) 2020;10:931-48.

69. Ekstein SF, Wyles SP, Moran SL, et al. Keloids: a review of therapeutic management. Int J Dermatol 2021;60:661-71.

70. Sullivan T, Smith J, Kermode J, et al. Rating the burn scar. J Burn Care Rehabil 1990;11:256-60.

71. Draaijers LJ, Tempelman FRH, Botman YAM, et al. The Patient and Observer Scar Assessment Scale: A Reliable and Feasible Tool for Scar Evaluation. Plast Reconstr Surg 2004;113:1960-5.

72. Verhaegen PD, van der Wal MBA, Middelkoop E, et al. Objective scar assessment tools: a clinimetric appraisal. Plast Reconstr Surg 2011;127:1561-70. 